\title{
Incidência de podridões do colmo, grãos ardidos e rendimento de grãos em híbridos de milho submetidos ao aumento na densidade de plantas
}

\author{
Ricardo Trezzi Casa, Eder Novaes Moreira, Amauri Bogo, Luís Sangoi
}

Universidade do Estado de Santa Catarina, Centro de Ciências Agroveterinárias - CAV/UDESC, Lages, SC, CP 281, 88520-000

Autor para correspondência: Ricardo Trezzi Casa, e-mail: a2rtc@cav.udesc.br

Data da chegada: 13/12/2005. Aceito para publicação em: 22/04/2007.

1303

\section{RESUMO}

Casa, R.T.; Moreira, E.N.; Bogo, A.; Sangoi, L. Incidência de podridões do colmo, grãos ardidos e rendimento de grãos em híbridos de milho submetidos ao aumento na densidade de plantas. Summa Phytopathologica, v.33, n.4, p.353-357, 2007.

A adequada combinação entre a escolha da densidade de plantas e do híbrido é um dos fatores que contribuem para o aumento da produtividade do milho. O objetivo deste trabalho foi avaliar o efeito do incremento na densidade de plantas sobre a incidência de podridões do colmo, de grãos ardidos e o rendimento de grãos de dois híbridos de milho contrastantes quanto a tolerância ao adensamento. O experimento foi conduzido em Lages, SC, nas safras agrícolas 2002/ 03 e 2003/04, em área de semeadura direta e monocultura, sob sucessão de cobertura morta constituída de aveia preta+ervilhaca. Estudou-se a combinação de dois fatores: híbrido e densidades, utilizando-se o delineamento experimental de blocos casualizados com parcela subdividida. Na parcela principal avaliaram os híbridos: Speed (simples, tolerante ao adensamento) e AG 303 (duplo, intolerante ao adensamento). Nas sub-parcelas testaram-se cinco densidades de plantas: 25, 50, 75, 100 e 125 mil plantas ha ${ }^{-1}$. O aumento da densidade de plantas, proporcionou incremento linear na incidência das podridões do colmo e grãos ardidos para os dois híbridos e duas safras avaliadas. O fungo Colletotrichum graminicola foi o mais detectado em colmos doentes, seguido do Fusarium graminearum, $F$. verticillioides e Stenocarpella $s p$. Nos grãos ardidos, os fungos predominantes foram $F$. verticillioides, F. graminearum e Penicillium spp. O híbrido AG 303 demonstrou menor resposta no rendimento do que o híbrido Speed com o aumento da população de plantas. Não foi observada associação direta entre o maior rendimento de grãos do híbrido simples em estandes adensados e a menor incidência de doenças de colmo e de grãos ardidos.

Palavras-chave adicionais: doenças, monocultura, plantio direto, população de plantas, Zea mays

\section{ABSTRACT}

Casa, R.T.; Moreira, E.N.; Bogo, A.; Sangoi, L. Incidence of stalk rot, rot grains and grain yield of maize hybrids submitted to the increase in plant density Summa Phytopathologica, v.33, n.4, p.353-357, 2007.

The combination between plant density and hybrid choice is an important factor to enhance maize grain yield. The objective of this work was to evaluate the increasing of plant density on the incidence of stalk rot, rot grains and grain yield of two maize hybrids with contrasting tolerance to crowding. The experiment was carried out in Lages-SC, during the crop seasons of 2002/03 and 2003/04, in an area of no-tillage and monoculture, having a mixture of black oat and vetch as the preceding winter crop. The experimental design was a randomized block with split plot arrangement and three replications per treatment. Two hybrids were evaluated in the main plots: Speed (a single-cross hybrid tolerant to crowding) and AG 303 (a doublecross hybrid intolerant to crowding). Each hybrid was submitted to five plant densities in the split-plots: $25,50,75,100$ and 125 thousand plants per ha. The increase in plant density enhanced linearly the occurrence of stalk rot and rot grains for both hybrids and crop seasons. The fungus Colletotrichum graminicola was detected with great frequency in the stalk rot, regardless of hybrid and crop season, followed by Fusarium graminearum, $F$. verticillioides and Stenocarpella sp. The predominant fungi in rot grains were $F$. verticillioides, $F$. graminearum and Penicillium spp. The grain yield of AG 303 was less responsive to the increment in plant density. No association between the higher grain yield of the single-cross hybrid Speed at dense stands and the lower incidence of stalk rot and rot grains was detected.

Additional Keywords: diseases, monoculture, no-till, plant density, Zea mays

O milho (Zea mays L.) é um dos cereais mais importantes economicamente da produção agrícola brasileira. Na safra agrícola de 2003/04, a área cultivada foi de aproximadamente 12,82 milhões de hectares, com produção total de 42,19 mil toneladas de grãos e rendimento médio de $3.291 \mathrm{~kg} \mathrm{ha}^{-1}$ (7).

Nessa cultura as doenças podem reduzir a produtividade $(14,18)$, e dentre elas, na Região Sul do Brasil, destacam-se, pela freqüência de ocorrência e danos causados, as relacionadas com a germinação de sementes, podridões do colmo e da espiga e algumas foliares causadas por fungos (6).

As podridões do colmo são caracterizadas pela descoloração na base das plantas, evidenciados principalmente a partir da maturação fisiológica do grão. Devido a alteração na consistência do feixe vascular das plantas infectadas há comprometimento da translocação de água e nutrientes do solo para a parte aérea da planta, com conseqüente redução no rendimento potencial e qualidade dos grãos (26). Fungos como Colletotrichum graminicola (Ces.) G.W. Wils, Fusarium graminearum $(\mathrm{Schw})$ Petch. (teleomorfo= Gibberella zeae), Fusarium 
verticillioides $[\operatorname{Sin} .=$ F. moniliforme J. Sheld.], Stenocarpella maydis (Berk.) Sutton [Sin. Diplodia maydis (Berk.) Sacc.] e S. macrospora (Earle) Sutton [Sin. D. macrospora Earle in Bull.], são os principais envolvidos nas podridões do colmo $(11,18)$. Exceção ao C. graminicola, os demais são comumente detectados nas podridões de espiga, com conseqüente redução do rendimento e qualidade de grãos, sendo que a presença de grãos ardidos reduz o preço de comercialização do produto.

O cultivo do milho em semeadura direta sob monocultura favorece a sobrevivência e multiplicação do inóculo dos fungos necrotróficos, levando ao incremento de podridões do colmo e da espiga $(16,25,8)$. A elevada densidade de plantas também é fator relevante para ocorrência de podridões do colmo (8) e da espiga (24). Altas populações impõem restrições à atividade fotossintética das folhas. A limitação imposta às folhas, induz o colmo a redirecionar fotoassimilados em maior quantidade ao enchimento de grãos, fragilizando-os e predispondo a ocorrência de podridões (21). Também patógenos causadores de podridões de colmo podem migrar, para a espiga, favorecendo a ocorrência de grãos ardidos (20). O efeito do incremento na densidade de plantas sobre a incidência de doenças depende do híbrido utilizado. Sangoi et al. (22) constataram que híbridos modernos de milho toleram mais ao adensamento quando comparados a híbridos utilizados no passado. É possível que este comportamento esteja relacionado com a maior sanidade do colmo e da espiga destes materiais mesmo sob altas densidades populacionais.

O objetivo do presente trabalho foi avaliar o efeito do incremento na densidade de plantas, na incidência de podridões de colmo, grãos ardidos e rendimento de grãos em dois híbridos de milho contrastantes quanto a tolerância ao adensamento.

\section{MATERIAL E MÉTODOS}

O ensaio foi conduzido no município de Lages, localizado no Planalto Sul de Santa Catarina, cujas coordenadas geográficas são $27^{\circ}$ $50^{\prime} 35^{\prime \prime}$ de latitude sul e $50^{\circ} 29^{\prime} 45^{\prime \prime}$ de longitude oeste. O solo da área experimental é classificado como Nitossolo Vermelho distrófico típico (10), apresentando, em 08/2002, as seguintes características: $560 \mathrm{~g} \mathrm{~kg}^{-}$ ${ }^{1}$ de argila, $\mathrm{pH}$ (em água) de 5,6; teores de fósforo, potássio e matéria orgânica de 2,9 mg L-1, $135 \mathrm{mg} \mathrm{L}^{-1}$ e $57 \mathrm{~g} \mathrm{~kg}^{-1}$, respectivamente.

O delineamento experimental foi de blocos casualizados, com parcelas subdivididas e, três repetições por tratamento, perfazendo um total de 30 parcelas. O espaçamento foi de $75 \mathrm{~cm}$ entre fileiras, com seis linhas de oito metros de comprimento por parcela.

Na parcela principal foram testados dois híbridos de milho: Speed, híbrido simples, liberado comercialmente para cultivo em 2002/2003, tolerante ao adensamento e, AG 303, híbrido duplo, liberado comercialmente para cultivo em meados da década de 80 , intolerante ao adensamento. Nas sub-parcelas, cada um dos híbridos foi avaliado em cinco densidades de plantas, equivalentes a 25, 50, 75, 100 e 125 mil plantas ha ${ }^{-1}$.

O ensaio foi implantado nas safras agrícolas de 2002/03 e 2003/ 04, em área sob semeadura direta e monocultura, em sucessão a cobertura morta de aveia preta+ervilhaca, dessecada, com o herbicida glifosato na dose $1.400 \mathrm{~g}$ i.a. ha ${ }^{-1}$.

A semeadura do milho foi realizada manualmente, em 22/11/2002 e 29/10/2003, aos 30 dias da dessecação da cobertura de inverno. Como prevenção ao ataque de pragas na fase de emergência das plântulas as sementes foram tratadas com inseticida tiametoxan (40 g i.a. para $100 \mathrm{~kg}$ de sementes). Na adubação de base foram aplicados $30 \mathrm{~kg}$ de N, $70 \mathrm{~kg}$ de $\mathrm{P}_{2} \mathrm{O}_{5}$ e $100 \mathrm{~kg}$ de $\mathrm{K}_{2} \mathrm{O}$ por ha- ${ }^{-1}$ e a adubação nitrogenada de cobertura realizada no momento em que as plantas apresentavam três, sete e onze folhas totalmente expandidas, aplicando-se $50 \mathrm{~kg}$ de $\mathrm{N} \mathrm{em}$ cada estádio fenológico. Imediatamente a semeadura foi aplicado uma combinação de atrazina (1.400 g i.a. ha $\left.{ }^{-1}\right)$ e metolachlor (2.100 g i.a. ha $\left.{ }^{-1}\right)$ sobre a superfície do solo para controle das plantas daninhas na préemergência. As densidades finais de plantas para os valores préestabelecidos em cada tratamento foram obtidas através de desbaste manual das plantas quando estas apresentavam três folhas totalmente expandidas.

A incidência de podridões do colmo foi determinada aproximadamente aos 25 dias da maturação fisiológica dos grãos, contando-se o número total de plantas e o número de plantas doentes, nas duas fileiras centrais de cada parcela. Para identificação das plantas doentes procedeu-se a remoção das folhas da base do colmo de todas as plantas para visualização da descoloração dos tecidos do colmo seguida do teste de resistência à pressão dos dedos polegar e indicador $(9,3,4)$.

Para determinação do rendimento de grãos foram colhidas, manualmente, todas as espigas das plantas das quatro fileiras centrais de cada parcela. Após estas foram despalhadas, trilhadas e os grãos secos em estufa até a obtenção de peso constante. Os grãos foram pesados e os valores convertidos em $\mathrm{kg} \mathrm{ha}^{-1}$ na umidade padrão de $13 \%$.

Na colheita, os colmos sintomáticos foram cortados e destinados ao Laboratório de Fitopatologia do CAV/UDESC, para posterior isolamento e, identificação de fungos. De cada colmo foi retirado um fragmento de $0,5 \mathrm{~cm}^{2}$ de tecido da região da medula, próximo ao nó; este desinfestado em hipoclorito de sódio à $1 \%$ durante 3 minutos; o excesso retirado com água estéril e, após os fragmentos transferidos para caixas gerbox contendo meio de cultura de BDA $+\mathrm{A}$ (batatadextrose-ágar + antibiótico $=200 \mathrm{mg} \mathrm{l}^{-1}$ de sulfato de estreptomicina). A incubação foi em câmara climatizada durante sete dias, a temperatura de $25^{\circ} \mathrm{C}$ e, fotoperíodo de $12 \mathrm{~h}$. A identificação dos fungos foi realizada com auxílio de lupa estereoscópica e microscópio ótico, tendo sido observadas as colônias dos fungos e a presença de esporos e corpos de frutificação.

Para determinação do percentual de grãos ardidos procedeu-se a separação manual dos sintomáticos (ardidos), dos sadios, em amostras com $250 \mathrm{~g}$ de grãos de cada parcela (2). Os grãos ardidos foram pesados e os valores transformados em percentagem. Para determinação da incidência de fungos nos grãos ardidos, foram selecionados visualmente 400 grãos sintomáticos, que após desinfestados com hipoclorito de sódio $1 \%$, foram plaqueados em meio de $\mathrm{BDA}+\mathrm{A}$ e incubados durante sete dias a temperatura de $25{ }^{\circ} \mathrm{C}$ com fotoperíodo de $12 \mathrm{~h}$. Foram considerados infectados aqueles sob os quais se desenvolveram colônias e/ou estruturas dos fungos, de acordo com metodologia proposta por Casa et al. (5) e Pinto (13), e os dados expressos em incidência para cada fungo detectado.

Os dados obtidos para incidência de podridões do colmo, grãos ardidos e rendimento de grãos foram submetidos à análise de variância e de regressão e analisados a um nível de significância de 5\% ( $\mathrm{P}<0,05)$.

\section{RESULTADOS E DISCUSSÃO}

Os resultados obtidos indicaram que o aumento na densidade de plantas levar ao incremento linear positivo significativo da incidência das podridões do colmo nos dois híbridos testados nas duas safras agrícolas (Figura 1). A maior densidade populacional, aumenta a competição intra-específica por água, luz e nutrientes, levando a predisposição da planta ao ataque de patógenos. Também o milho cultivado em sistema de monocultura pode favorecer no sentido de 

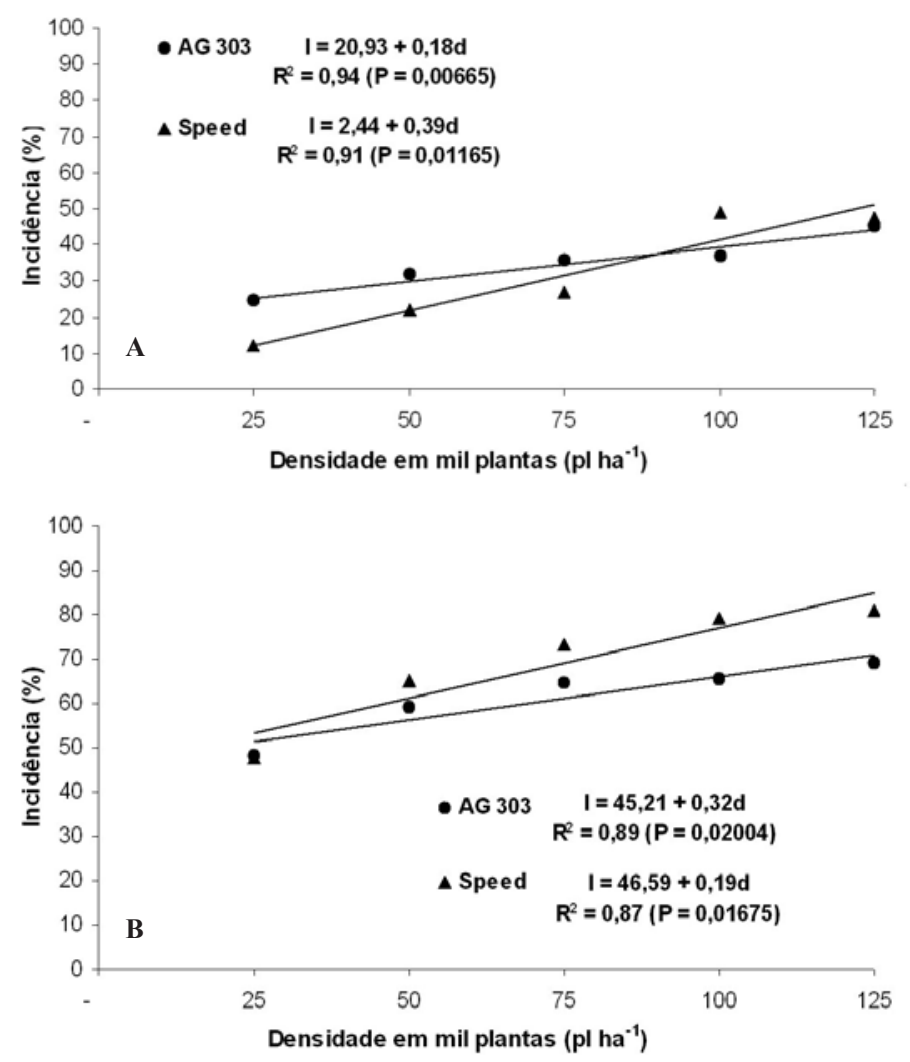

Figura 1. Efeito da densidade de plantas (d) na incidência (I) de podridão de colmo nos híbridos de milho AG-303 e Speed. Safras agrícolas 2002/03 (A) e 2003/04 (B), Lages, SC.

aumentar a incidência das doenças. Denti \& Reis (8) e Trento et al. (24) relataram aumento na intensidade de doenças no colmo e espigas em maiores densidades de plantas, em área sob plantio direto e monocultura.

Na comparação entre os híbridos, o simples Speed foi o que apresentou maior incidência de podridões do colmo na safra 2003/04. Comparando safras agrícola, os percentuais de incidência de podridões do colmo foram maiores em 2003/04 (Figura 1).

Tabela 1. Fungos isolados de podridões do colmo nos híbridos de milho AG 303 e Speed submetidos ao aumento na densidade de plantas.Safras agrícolas 2003 e 2004, Lages, SC.

\begin{tabular}{|c|c|c|c|c|c|}
\hline \multirow{3}{*}{ Fungos } & \multirow{3}{*}{$\begin{array}{c}\text { Densidade em } \\
\text { mil plantas } \\
\left.(\mathrm{pl} \mathrm{ha})^{-1}\right)\end{array}$} & \multicolumn{4}{|c|}{ Incidência de fungos $(\%)$} \\
\hline & & \multicolumn{2}{|c|}{ Safra 2003} & \multicolumn{2}{|c|}{ Safra 2004} \\
\hline & & AG 303 & Speed & AG 303 & Speed \\
\hline \multirow{5}{*}{$\begin{array}{l}\text { Colletotrichum } \\
\text { graminicola }\end{array}$} & 25 & 18,4 & 11,1 & 42,1 & 34,4 \\
\hline & 50 & 28,6 & 14,2 & 46,1 & 28,3 \\
\hline & 75 & 31,8 & 22,4 & 54,6 & 44,8 \\
\hline & 100 & 29,1 & 35,8 & 63,1 & 49,0 \\
\hline & 125 & 35,4 & 38,4 & 66,4 & 50,5 \\
\hline Fusarium & 25 & 5,1 & 2,0 & 20,4 & 17,7 \\
\hline \multirow{4}{*}{ gramineartm } & 50 & 1,1 & 1,1 & 16,7 & 9,4 \\
\hline & 75 & 4,5 & 3,6 & 19,5 & 6,9 \\
\hline & 100 & 8,1 & 2,8 & 12,5 & 5,3 \\
\hline & 125 & 5,8 & 3,0 & 18 & 7,0 \\
\hline Fusarium & 25 & 2,1 & 2,1 & 8,2 & 6,3 \\
\hline \multirow[t]{4}{*}{ verticillioides } & 50 & 1,1 & 2,2 & 9,1 & 6,7 \\
\hline & 75 & 2,3 & 1,5 & 3,1 & 2,5 \\
\hline & 100 & 0,6 & 1,7 & 3,1 & 4,1 \\
\hline & 125 & 1,0 & 1,5 & 4,1 & 4,2 \\
\hline Stenocarpella & 25 & 1,0 & 4,1 & 14,5 & 16,7 \\
\hline \multirow[t]{4}{*}{ sp. } & 50 & 2,2 & 3,3 & 14,7 & 11,1 \\
\hline & 75 & 1,5 & 1,5 & 10,4 & 13,0 \\
\hline & 100 & 1,1 & 1,1 & 5,1 & 4,4 \\
\hline & 125 & 1,0 & 1,0 & 3,8 & 49 \\
\hline
\end{tabular}

Nas duas safras e nos dois híbridos, os fungos patogênicos detectados mais freqüentes e com maior incidência nos colmos sintomáticos foram C. graminicola e F. graminearum (Tabela 1). A maior incidência de $C$. graminicola pode ser justificada devido a existência de hospedeiros secundários do patógeno presentes na lavoura, como Brachiaria plantaginea L. e Digitaria sanguinalis L. e, pela cobertura de inverno a aveia preta (Avena strigosa L.), que garantem a sobrevivência do patógeno (19). Denti \& Reis (9), também relataram C. graminicola como o patógeno mais freqüente em levantamento de podridões do colmo realizado na região do Planalto do Rio Grande do Sul e Campos Gerais do Paraná. Também nas maiores densidades houve tendência para maior incidência de C. graminicola (Tabela 1), provavelmente devido a maior predisposição das plantas à infecção, pois a demanda por água e nutrientes também é incrementada em altas populações. Em relação aos híbridos, o AG 303 foi mais suscetível à C. graminicola na safra 2004 (Tabela 1). A detecção de $F$. graminearum também está relacionada com a presença de gramíneas na área de cultivo $(17,19)$. Os fungos $F$. verticilliodes e Stenocarpella sp. foram observados nos dois anos independente das densidades de semeaduras, com maior incidência na safra 2004, podendo isso ter ocorrido devido a mais um ano de monocultura. Cephalosporium sp. e Nigrospora sp. foram observados, mas com menor incidência.

Para rendimento de grãos nos dois híbridos a reação foi diferente do incremento na densidade de plantas. Para o híbrido contemporâneo Speed, o maior rendimento foi nas densidades mais altas (Figura 2), enquanto que para o híbrido antigo AG 303, populações superiores a $50.000 \mathrm{pl} \mathrm{ha}^{-1}$ proporcionaram decréscimos no rendimento de grãos na safra 2003/04 (Figura 2B).

O híbrido Speed foi o que apresentou maior rendimento de
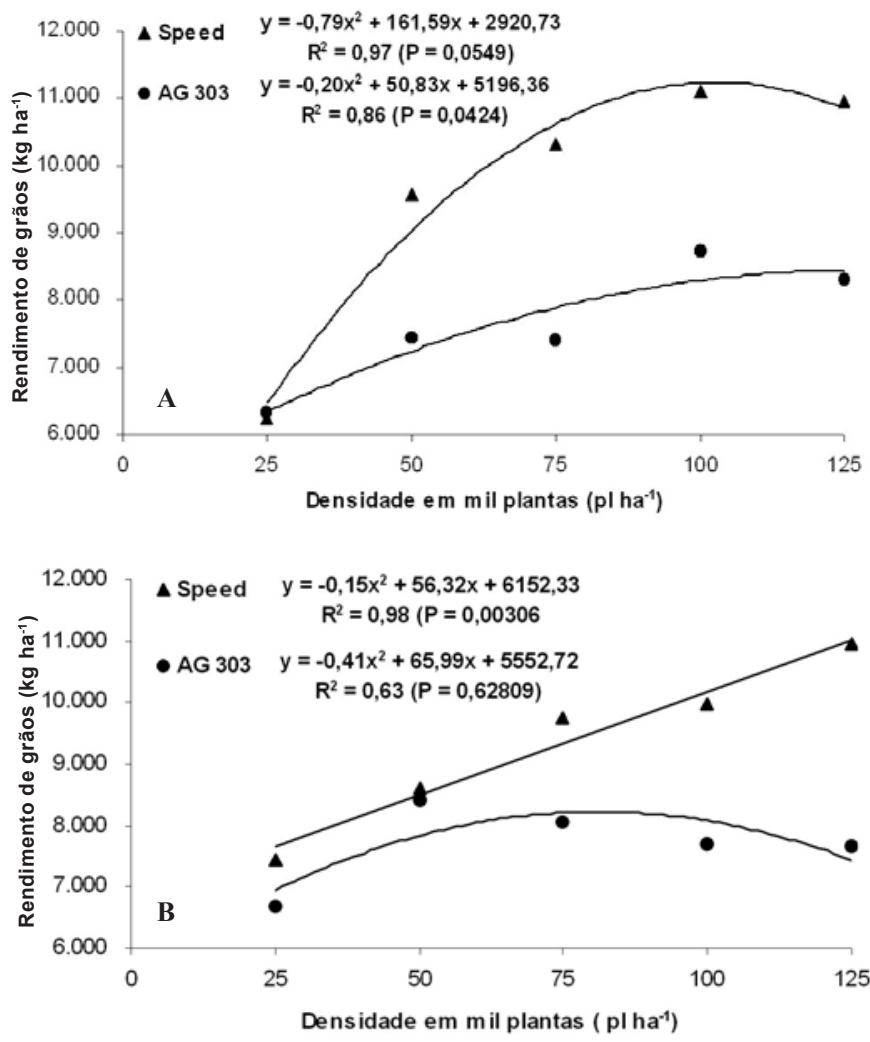

Figura 2. Rendimento de grãos de milho (x) nos híbridos AG-303 e Speed submetidos ao aumento na densidade de plantas. Safras agrícolas 2002/03 (A) e 2003/04 (B), Lages, SC. 
grãos nas duas safras e, em todas densidades (Figura 2). As diferenças de produtividade entre os dois genótipos se acentuaram com o incremento na densidade de plantas. Isto provavelmente ocorreu porque o Speed é um híbrido simples adaptado a altas densidades populacionais. Híbridos simples possuem maior heterose do que híbridos duplos, o que eleva seu potencial produtivo sob condições favoráveis de manejo (1). Também a variabilidade morfológica e fenológica entre plantas é menor nos híbridos simples, que ocorre, segundo Tokatlidis \& Koutroubas (23) e Liu et al. (12), pela diminuição da competição intra-específica sob altas densidades de plantas, melhorando a adaptação ao adensamento.

Não foram realizadas correlações entre a incidência de podridões no colmo e rendimento de grãos. Porém, o híbrido Speed mostrou-se mais suscetível a podridão do colmo nas maiores densidades onde obteve maior rendimento, demonstrando, que mesmo sob maior incidência de doença, pode não sofrer redução no rendimento de grãos. Essa mesma situação foi observada para nove híbridos de milho quando do levantamento de incidência e de danos causados por podridões do colmo em três municípios catarinenses (4).

O incremento na densidade de plantas levou a maior incidência de grãos ardidos nos dois híbridos e anos agrícolas (Figura 3). O percentual de grãos ardidos e incidência de podridão do colmo foi maior no ano agrícola de 2002/03 (Figuras 1 e 3). Como patógenos de colmo podem atacar a espiga, esse pode ser um fator da maior incidência de grãos ardidos no primeiro ano de condução dos trabalhos.

O híbrido AG 303 apresentou maior percentagem de grãos ardidos em 2002/2003 (Figura 3A). O contrário ocorreu em 2003/04, quando os valores foram maiores no Speed, em todas as densidades de
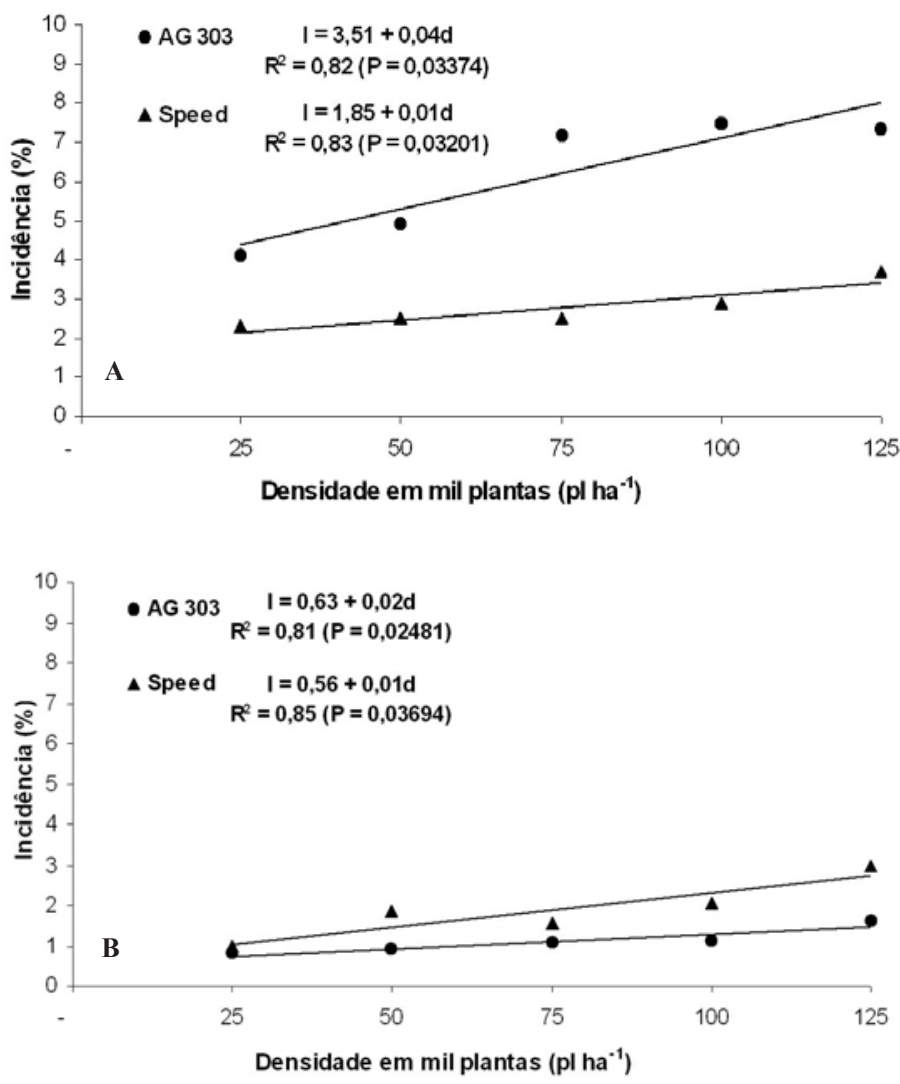

Figura 3. Efeito da densidade de plantas (d) na incidência (I) de grãos ardidos nos híbridos AG-303 e Speed. Safras agrícolas 2002/03 (A) e 2003/ 04 (B), Lages, SC. semeadura (Figura 3B). De modo geral, os valores médios de percentagem de grãos ardidos foram baixos para os dois híbridos, nas diferentes densidades de plantas (Figura 3), se comparados com o valor mínimo de $6 \%$ adotado por empresas, para desconto no momento da comercialização do grão.

Nos grãos ardidos os fungos mais freqüentes foram $F$. verticillioides, F. graminearum, Penicillium ssp., S. macrospora e S. maydis, respectivamente. A infecção de patógenos na espiga ocorre durante e,ou, logo após a polinização do milho $(26,18)$. O $F$. verticillioides foi o mais freqüente, com incidência de $3,4 \%$ no AG 303 na densidade de 25 mil plantas ha ${ }^{-1}$ e 36,7\% no Speed na densidade de 125 mil plantas ha- ${ }^{-1}$. F verticillioides é uma das espécies de Fusarium produtoras de micotoxinas (15), as quais depreciam a qualidade do grão.

O incremento na densidade de plantas é uma das maneiras para aumentar a interceptação da radiação solar e elevar o rendimento de grãos da cultura do milho, entretanto essa prática de manejo também pode favorecer a incidência de podridões de colmo e de grãos ardidos. Os resultados obtidos neste trabalho permitem concluir que a adoção de densidade de plantas adequada para o híbrido, somada a utilização de sementes sadias e a semeadura em área de plantio direto sob rotação de culturas com soja ou feijão, são fatores que podem contribuir para a redução da incidência de podridões de colmo e grãos ardidos e o aumento do rendimento de grãos do milho em maiores populações de plantas.

\section{REFERÊNCIAS BIBLIOGRÁFICAS}

1. Borém, A. Melhoramento de espécies cultivadas. Viçosa: UFV, 1999. $817 \mathrm{p}$.

2. Brasil. Portaria $n^{0} 11$. Estabelece critérios complementares para classificação do milho. Diário Oficial da União, Brasília, DF, 12 de abril de 1996. n 72.

3. Casa, R.T.; Blum, M.M.C.; Fontoura, S.M.V. Efeito do pré-cultivo de aveia branca e nabo forrageiro sobre a incidência de podridões do colmo, de grãos ardidos, de fungos nos grãos e sobre o rendimento de grãos de diferentes híbridos de milho. Summa Phytopathologica, Botucatu, v. 31, n.3, p. 241-246, 2005.

4. Casa, R.T.; Moreira, E.N.; Rizzi, F.P.; Ahmad, J.; Gobbi, E.; Erhart, J. Incidência e danos de podridões do colmo em genótipos de milho em três localidades de Santa Catarina. In: Reunião técnica catarinense de milho e feijão, 5., 2005, Chapecó. Anais.Chapecó: Newsprint, 2005. v. 1, p. 138-141.

5. Casa R.T.; Reis, E.M.; Zambolim, L. Fungos associados à semente de milho produzida nas Regiões Sul e Sudeste do Brasil. Fitopatologia Brasileira, Brasília, v.23, n.3, 370-373, 1998.

6. Casa, R.T.; Reis, E.M.; Severo, R.; Denti, E.; Trento, S.; Blum, M.M.C. Prevenção e controle de doenças na cultura do milho. In: Sandini, I.A.; Fancelli, A.L. Milho: estratégias de manejo para a região sul. Guarapuava: Fundação Agrária de Pesquisa Agropecuária, 2000. 209 p.

7. Conab. Indicadores da Agropecuária. Brasília, DF, 2005. Disponível em: http://www.conab.gov.br. Acesso em 20 jan. 2005.

8. Denti, E.A.; Reis, E.M. Efeito da rotação de culturas, da monocultura e da densidade de semeadura de plantas na incidência das podridões da base do colmo e no rendimento de grãos do milho. Fitopatologia Brasileira, Brasília, v.26, n.3, 635-639, 2001.

9. Denti, E.A.; Reis, E.M. Levantamento de fungos associados às podridões do colmo e quantificação de danos em lavouras de milho do Planalto Médio Gaúcho e Campos Gerais do Paraná. Fitopatologia Brasileira, Brasília, v.28, n.6, p.585-590, 2003.

10. Embrapa. Centro Nacional de Pesquisa de Solos. Sistema Brasileiro de Classificação de Solos. Brasília: Embrapa, 1999. 412p.

11. Fernandes, F.T.; Oliveira, E. de. Principais doenças na cultura do milho. Circular Técnica EMBRAPA CNPMS, Sete Lagoas, n.26, 1997. $80 \mathrm{p}$. 
12. Liu, W.; Tollenaar, M.; Stewart, G.; Deen, W. Response of corn grain yield to spatial and temporal variability in emergence. Crop Science, Madison, v.44, n. 3, p.847-857, 2004.

13. Pinto N.F.J. de A. Patologia de sementes de milho. Circular Técnica EMBRAPA CNPMS, Sete Lagoas, n.29, 1998. 44p.

14. Pinto, N.F.J. de A.; Fernandes, F.T.; Oliveira, E. Milho. In: Vale, F.X.R.; Zambolim, L. (Ed.). Controle de doenças de plantas: grandes culturas. Viçosa, MG: UFV, Departamento de Fitopatologia; Brasília, DF: Ministério da Agricultura e do Abastecimento, 1997. p.821-863.

15. Reid, L.M.; Nicol, R.W.; Ouellet, T.; Savard, M.; Miller, J.D.; Young, J.C.; Atewart, D.W.; Schaafsma, A.W. Interaction of Fusarium graminearum and $F$. moniliforme in maize ears: disease progress, fungal biomass, and mycotoxin accumulation. Phytophatology, St. Paul, v.89, n..11, p.1028-1037, 1999.

16. Reis, E.M.; Casa, R.T. Controle de doenças fúngicas na cultura do milho em semeadura direta. In: Seminário sobre tecnologia de produção e comercialização do milho, 2000, Passo Fundo, RS. Resumo de Palestras. Passo Fundo: Aldeia Norte, 2000, p.6271 .

17. Reis, E.M.; Casa, R.T. Sobrevivência de fitopatógenos. In: Vale, F.X.R.; Jesus Junior, W.C.; Zambolim, L. (Org.). Epidemiologia aplicada ao manejo de doenças de plantas. Belo Horizonte, 2004, p.337-364.

18. Reis, E.M.; Casa, R.T.; Bresolim, A.C.R. Manual de diagnose e controle de doenças de milho. Lages: Graphel, 2004. 144p.

19. Reis, E.M.; Casa, R.T.; Medeiros, C.A. Diagnose, patometria e controle de doenças de cereais de inverno. Londrina: Criação e editoração ES Comunicações, 2001. 94p.

20. Ribeiro, N.A.; Casa, R.T.; Bogo, A.; Sangoi, L.; Moreira, E.N.; Wille, L.A. Incidência de podridões do colmo, grãos ardidos e produtividade de grãos de genótipos de milho em diferentes sistemas de manejo. Ciência Rural, Santa Maria, v.35, n.5, p.1003$1009,2005$.

21. Sangoi, L.; Ender, M.; Guidolin, A.F.; Bogo, A.; Kothe, D.M. Incidência e severidade de doenças de quatro híbridos de milho cultivados em diferentes densidades de planta. Ciência Rural, Santa Maria, v.30, n.1, p.17-21, 2000.

22. Sangoi, L.; Gracietti, M.A.; Rampazzo, C.; Bianchet, P. Response of Brazilian maize hybrids from different eras to changes in plant density. Field Crops Research, Amsterdan, v.79, p.39-51, 2002.

23. Tokatlidis, I.S.; Koutroubas, S.D. A review of maize hybrids' dependence on high plant populations and its implications for crop yield stability. Field Crops Research, Amsterdan, v.88, n.1, p.103-114, 2004.

24. Trento, S.M.; Irgang, H.H.; Reis, E.M. Efeito da rotação de culturas, da monocultura e da densidade de plantas na incidência de grãos ardidos em milho. Fitopatologia Brasileira, Fortaleza, v.27, n.6, p.609-613, 2002

25. Zambolim, L.; Casa, R.T.; Reis, E.M. Sistema semeadura direta e doenças em plantas. Fitopatologia Brasileira, Fortaleza, v.25, n.4, p.585-595. 2000.

26. White, D.G. Compendium of corn diseases. $3^{\text {rd }}$ ed. St. Paul: APS, 1999. 78p. 